\title{
IMPLANTAÇÃO DO SISTEMA 5S DE QUALIDADE, COMO FERRAMENTA DE MELHORIAS EM UM SERVIÇO DE REFEIÇÃO A EDUCANDOS EM UMA ESCOLA PARTICULAR NO INTERIOR DE SÃO PAULO
}

Implementation of the $5 s$ quality system, as a tool for improvements in a meal service to educants at a particular school in the interior of São Paulo, Brazil.

${ }^{1}$ Márcia Adrielly Bulgarelli Tonon, ${ }^{2}$ Vanessa Fernandes Coutinho, ${ }^{3}$ Renato Ribeiro Nogueira Ferraz

${ }^{1-3}$ Universidade Estácio de Sá - SP.

\section{RESUMO}

Este relato teve como objetivo mostrar como a implantação do Programa 5S pode melhorar a qualidade do serviço e trazer benefícios a instituição e colaboradores. Foi realizado uma análise do Serviço de Refeição aos Educandos, onde foram observados a estrutura física, os procedimentos realizados e relatórios administrativos. A aplicação da ferramenta possibilitou a melhora na qualidade do serviço, além de maior lucratividade e bem-estar dos funcionários. Palavras-chave: gestão de qualidade; Programa 5S; serviço de alimentação.

\section{ABSTRACT}

This report aimed to show how the implementation of the 5S Program can improve the quality of service and bring benefits to the institution and employees. An analysis of the Meal Service for the Educandos was carried out, where the physical structure, the procedures performed and administrative reports were observed. The application of the tool made possible the improvement in the quality of the service, besides greater profitability and well-being of the employees.

Keywords: quality management; 5S Program; food service.

\section{INTRODUÇÃO}

O Serviço de Refeição a Educandos (SRE), objeto de estudo presente no relato, foi criado com a finalidade de oferecer um espaço no qual os estudantes de faixa etária de 6 a 17 anos pudessem dispor de lanches e almoço diversificados e nutritivos sem se preocuparem com a qualidade e segurança alimentar. A estrutura é composta por uma cozinha industrial, dividida por área de recebimento de mercadoria, estoque, área de pré-preparo, preparo e distribuição das refeições, refeitório e a área de lavagem de utensílios e panelas. Para o funcionamento do serviço o mesmo dispõe de 1 nutricionista, 1 cozinheira e 3 ajudantes de cozinha.

O Programa $5 \mathrm{~s}$ foi elaborado para que cada organização possa criar o seu próprio programa de qualidade, conscientizando seus colaboradores sobre a importância de ter um ambiente saudável e harmonioso. No SRE o programa foi implantado em busca da qualidade dos serviços, uma vez que percebeu-se que o gerenciamento possuía falhas e precisava de melhorias, pois alguns processos estava influenciando negativamente na sua funcionalidade e obtenção de resultados, entre eles estavam as falhas na aquisição e controle de gêneros alimentícios , utensílios e equipamentos armazenado em estoque sem previsão de uso, quadro de funcionário desajustado e com falta de qualificação e a dificuldade da obtenção de resultado no custo final.

Assim, esse relato tem como objetivo principal apresentar como foi realizada a adoção do sistema $5 \mathrm{~s}$ de qualidade para obtenção de melhorias no SRE, através das mudanças no ambiente de trabalho, programas de qualidade de vida, qualidade de serviços e controle de custos. 
Com este fim, este estudo está estruturado em 4 seções, além dessa breve introdução. A primeira seção apresenta a revisão teórica-empírica do estudo. Na seção seguinte é apresentado o método empírico e na próxima são apresentados e analisados os resultados do levantamento conduzido. E finalmente na quarta seção, são realizadas as considerações finais dos autores.

\section{REFERENCIAL TEÓRICO}

De acordo com Silva (2011), programa 5s, foi desenvolvido por Kaoru Ishikawa na década de 50, com o objetivo de suprir as necessidades do Japão, no pós-Guerra. Devido a sua eficácia em reorganizar as empresas e a economia japonesa, atualmente é o principal instrumento de gestão da qualidade e da 13 produtividade utilizado naquele país.

$\mathrm{O}$ " $5 \mathrm{~S}$ " é um conjunto de cinco atividades que iniciam pela letra "S", quando pronunciadas em japonês: SEIRI - Senso de Utilização, separar o necessário do que é desnecessário; SEITON Senso de Arrumação, identificar e arrumar tudo, para que outras pessoas também possam localizar objetos, documentos e outros facilmente; SEISO - Senso de Limpeza; manter um ambiente sempre limpo, eliminando as causas da sujeira, e aprendendo a não sujar; SEIKETSU - Senso de Saúde e Higiene; manter um ambiente de trabalho sempre favorável à saúde e higiene; SHITSUKE - Senso de Autodisciplina, criar condições favoráveis à saúde física e mental, manter boas condições sanitárias nas áreas comuns, zelar pela higiene pessoal e cuidar para que as informações e comunicados sejam claros, de fácil leitura e compreensão.

$\mathrm{O}$ "5S" tem como objetivo a valorização do indivíduo; promover a alteração no comportamento de cada pessoa, ou seja, fazer com que tenha consciência do que é certo e errado para o seu ambiente de trabalho, reduzir custos, melhorar as relações humanas eliminando atividades que não agreguem valores pessoais e profissionais, trabalhar com mais segurança (separando o que é necessário do que não é necessário), fazendo assim que obtenha maior eficiência da qualidade tanto pessoal quanto profissional (SILVA,2011).

Já de acordo com Rabello (2005), os sensos têm como objetivo promover as alterações de comportamento na equipe (pessoas) e transformar para melhor o ambiente das organizações. $\mathrm{Na}$ determinação do Programa 5S do presente relato, o mesmo foi utilizado pois segundo Habu et al (1992) "O 5S traz a melhoria da estrutura da empresa, sendo que, para tal, o método de abordagem adequado é a execução antes da teorização. Com a realização do $5 S$ até o nível de uma crença, os resultados obtidos são extremamente grandes tanto em termos quantitativos quanto qualitativo". A escolha desse método deveu pois segundo Mitki e Shani (1996) "a Gestão da Qualidade Total é uma abordagem para melhorar processos numa organização com o intuito de oferecer bens, produtos elou serviços, que satisfarão o consumidor" e o sistema 5S é umas das principais ferramentas de Gestão de Qualidade Total.

Ricardo Carvalho Nascimento, diretor do Grupo Ferroeste, afirma que a implantação do Programa 5S foi fundamental para a empresa, uma vez que proporcionou um ambiente de trabalho seguro e organizada para seus funcionários e contribuiu para melhorias em processos produtivos e administrativo da empresa (GRUPO FERROESTE, 2018). Com o mesmo objetivo do Grupo Ferroeste o Rodrigo Grave, Coordenador do Programa 5S na empresa Univale vem desde 2013 implantando o sistema de qualidade (UNIVALE, 2018).

Rabello (2005), que participou da implantação do Programa na Biblioteca dentro do Hospital da USP, notou que o mesmo proporcionou uma reorganização na Biblioteca, devido as mudanças no ambiente físico, nos processos organizacionais, que contribuiu para a melhoria da autoestima dos colaboradores, provocando também o relacionamento entre os setores do hospital. Além de ambientes limpos e organizados, diminuição de desperdícios de materiais, motivação, flexibilidade nas relações sociais entre funcionários, espírito de equipe, elevação da moral dos funcionários e maior comprometimento com a instituição. 


\section{ASPECTOS METODOLÓGICOS}

O Serviço de Refeição aos Educandos encontra-se em uma escola particular que atende crianças e adolescentes, com renda baixa, média e alta, situada na cidade de Itapira, município localizado no interior de São Paulo. Cidade pequena, com aproximadamente 73 mil habitantes (IBGE 2017), fundada em 1800 por João Gonçalves de Morais e Manuel Pereira da Silva. Conhecida regionalmente pelas pessoas como a cidade dos loucos. Famosa por seus cuidados clínicos psiquiátricos, Itapira possui três grandes hospitais psiquiátrico, sendo um deles o Instituto Bairral de Psiquiatria, conhecido mundialmente por ser um dos maiores da América (PREFEITURA DE ITAPIRA,2017).

O Serviço de Refeição aos Educandos percebendo que não estava obtendo os resultados planejados, foi em busca de ferramentas para conseguir aprimorar sua unidade produtora de alimentos, visto que a mesma tinha armazenado em estoque grande volume de gêneros alimentícios seco (arroz, feijão, maionese), perecíveis (carnes, iogurtes, frios, polpas), além de utensílios e equipamentos sem utilidades (copos, bandejas, batedeiras, liquidificador). Outro fator observado foi a distribuição das áreas (área de preparo, de cocção, lavagem de panela, higienização de utensílios, estoque) que poderiam ser distribuídas de uma maneira diferente facilitando as atividades desenvolvidas em cada uma, e consequentemente diminuir a transição pela cozinha e facilitar os acessos aos utensílios e equipamentos necessários para cada área.

Percebeu-se também que precisaria, qualificar e melhorar a saúde físico-mental dos seus funcionários, uma vez que o ambiente é propicio ao estresse e acidentes de trabalho, o que diminuía a motivação e influenciava no desempenho dos mesmos, problema enorme para a empresa, visto que mão de obra local da pequena cidade nem sempre atende com as necessidades dos cargos (qualificação e experiência) tornando assim responsabilidade da empresa a qualificação de seus funcionários para a execução de suas tarefas.

Após a análise dos fatores que precisavam ser melhorados na unidade, entendeu-se que se implantado o sistema de qualidade $5 \mathrm{~s}$, conseguiríamos através de novas ferramentas resultados positivos, sendo o objetivo maior controle e gerenciamento de estoques, para evitarse acúmulos e perdas de gêneros alimentícios; desfazer de equipamentos e utensílios sem utilidades para conseguir um ambiente organizado e com maior espaço, reorganizar áreas da cozinha para diminuir a circulação pela mesma ganhando tempo das funcionárias nas suas tarefas e por fim qualificar e criar programas para manter os funcionários motivados e com saúde física-mental, para que consigam atingir os resultados não só financeiros, mas também referente a qualidade do serviço para com os clientes (alunos comensais).

\section{APRESENTAÇÃO E ANÁLISE DOS RESULTADOS}

Ao analisar o Serviço de Refeição aos Educandos, foram observados dados gerenciais no qual apontavam os custos da unidade (lucro e prejuízo) e planilhas administrativas a qual descrevia onde o dinheiro da empresa estava sendo investido (mão de obra, aquisição de gêneros alimentícios gerais, equipamentos, utensílios e a quantidade de aluno que adquiriam as refeições nos dias). Foi observado também a dimensão da estrutura e divisões de área (recebimento de mercadorias, pré-preparo, preparo, distribuição, higienização e estoque) e como estava ocorrendo os processos para a preparação dos alimentos/refeições e às realizações das tarefas diárias desde o recebimento até o descarte das preparações servidas e higienização não só dos utensílios como também equipamentos e instalações.

Em reunião com os colaboradores, ocorreu os levantamentos de como saúde físicomental dos mesmos estavam, e foi solicitado que cada um comentasse um pouco do que fazia, como fazia e como ele achava que poderia melhorar nas tarefas que executava diariamente.

Após a análise, notou-se que a unidade de serviço de alimentação não estava atingindo sua meta referente aos lucros e custos; havia excessos de gêneros alimentícios, equipamentos e utensílios no estoque sem previsão de uso ou manutenção; as divisões das áreas poderiam ser 
melhor distribuídas, com o intuito de melhorar a transição; não havia padrão para as tarefas executas pelos colaboradores; os colaboradores estavam exaustos, desmotivados e estressados com a rotina; além de dúvidas de como executar alguns procedimentos. Com o intuito de melhorias, o programa $5 \mathrm{~S}$ começou a ser implantado por partes, conforme segue.

\section{SEIRI}

Conhecido como o senso da utilização, consiste em deixar no ambiente de trabalho realmente aquilo que se é extremamente necessário. Representa utilizar os recursos disponíveis, identificando aquilo que seja desnecessário e eliminando-o. Sendo eliminado não apenas coisas materiais, mas também tarefas e processos, além de fazer com que ocorra o questionamento do porquê do excesso (GOMES et al., 1998).

O primeiro senso a ser utilizado foi o SEIRI e com base nesse senso, começou-se a realizar um planejamento mensal de cardápio, com cálculos de per capta (quantidade de determinados alimentos por pessoa) mínimo para que não só ocorra menor acumulo de gêneros no estoque, mas também diminua o desperdício (resto ingesta, quantidade de comida feita e não consumida). Os alimentos que já estavam estocados e não tinham previsão de consumo foram doados para uma instituição de baixa renda na cidade. Os equipamentos que já não funcionavam mais foram descartados, e o mesmo ocorreu com os utensílios que não seriam mais utilizados.

Vassouras, rodos e outros materiais de limpeza e descartáveis começaram a ser contabilizados e os que já estavam com o número superior do usável no serviço foram devolvidos e/ou transferido para outras unidades de alimentação. Papéis arquivados com mais de 5 anos foram eliminados e se necessário enviados para o arquivo morto na sede, uma vez que não terá utilidade onde se encontra. Alguns processos foram modificados, para que ocorra um melhor rendimento, entre eles a verificação de temperatura de equipamentos em 3 horários diferentes no dia, começou apenas verificar a temperatura no período da manhã e só quando o equipamento se apresenta com algum defeito a temperatura era verificada com maior frequência.

\section{SEITON}

O senso da arrumação foi aplicado logo em seguida, ao senso da utilização. De acordo com Habu et al (1992), o senso da arrumação ou também conhecido como o sendo da ordenação é definido como "um otimizador da área de trabalho", uma vez que consiste em definir local e critérios para o armazenamento, fazendo com que as coisas necessárias sejam utilizadas com velocidade e segurança.

Para Rebello (2005), esse senso significa organizar cada objeto em seu único e exclusivo lugar, para que possam ser utilizados prontamente. Afirma também que o SEITON possibilita que o local de trabalho se mantenha organizado e promove ações que facilitam o trabalho, permitindo assim que todos os colaboradores saibam onde encontrar o que precisa.

Com o intuito de otimizar processos, houve uma reorganização dos utensílios, os mesmos foram separados conforme sua utilidade e armazenado em caixas transparentes com tampas, além de etiquetas de identificação, para que quando fosse necessário esteja de fácil acesso e localização. Planilhas, relatórios gerenciais, manual de boas práticas e outros documentos, também foram reorganizado para que todos tivessem acesso quando necessário em prateleiras no armário separados por pastas etiquetadas. Também foram separados e armazenados em locais de fácil acesso a todos, os materiais de limpeza e descartáveis, alguns separados por caixas transparentes e outros expostos em estantes por grupo.

\section{SEISO}


Lapa (1998) disse: "Poeira, lama, lixo, apares e outros nos locais de trabalho, podem não somente influenciar negativamente na saúde e integridade dos executantes como também causar danos, defeitos e falhas em equipamentos. $O$ resultado disto são quebras inesperadas de equipamentos, ferramentas não disponíveis, deterioração de peças e materiais etc.”. Esse senso consiste em eliminar sujeira e seus causadores, para manter o ambiente de trabalho limpo, organizado e agradável proporcionando qualidade de vida (RABELLO, 2005). A filosofia geral desse senso não consiste no ato de limpar mais sim em aprender a não sujar (LAPA, 1998).

Baseado nesse conceito foi realizado um treinamento com os colaboradores reforçando como deve se limpar os utensílios, equipamentos e instalações seguindo sempre o recomendado pela legislação, e acordado com os mesmo que sempre que utilizar e sujar algo, imediatamente após o uso será o responsável pela limpeza que deverá ser imediata, para que assim o ambiente se mantenha organizado.

\section{SEIKETSU}

Esse senso refere-se à execução aos sensos anteriores de uma maneira sistematizada, ou seja, manter o descarte, a organização e implantar o padrão de limpeza, tendo sempre a atenção com a própria saúde físico, mental e emocional. Tem como resultado a padronização de forma sistematizada com manutenção e monitorização para que não ocorra o retrocesso das aplicações dos sensos. De acordo com Calegare (1999) o objetivo da padronização e fazer com que as tarefas sejam cumpridas voluntariamente e de forma rotineira para que os resultados sejam alcançados a fim de melhorar o desempenho da organização.

Em busca da melhoria da produtividade e do ambiente do trabalho, foram realizados reuniões e treinamentos dos colaboradores envolvidos, onde se discutia sobre os procedimentos que estavam sendo realizados, quais as melhores formas para realizar o mesmo e como alcançar os objetivos, para que toda a equipe pudesse se envolver e criar hábitos para amenizar os estresses da rotina.

\section{SHITSUKE}

Rabello (2005) diz que esse senso significa ser responsável pela qualidade do seu trabalho e de sua vida, sempre buscando melhorias ao cumprir os padrões técnicos, éticos e morais, normas e tudo o que estabelecido pela organização. É o pacto da qualidade onde assumimos o compromisso acordado nos outros sensos, afim de aperfeiçoar e continuar a aplicação do programa.

Esse senso assim como o anterior (SEIKETSU), foi através de discussão com os membros da equipe, onde sempre se ressaltava a importância do mesmo seja no grupo ou de forma individual, fazendo-o compreender o quão importante eram as suas atitudes executadas no trabalho, mostrando os resultados já alcançados e os que ainda estavam por vir.

Pode-se dizer que as aplicações dos sensos acima relatas contribuíram de forma imediata para diminuir os desperdício e percas, uma vez que os estoques começaram a ser melhor controlado, planejados e sem exageros, onde não só ocorreu um aumento na lucratividade ao decorrer dos dias, mas uma melhora significativa na qualidade do serviço junto ao cliente. A equipe teve aos poucos um aumento no seu rendimento operacional, o que permitiu aos mesmos, momentos menos estressantes, tornando o ambiente de trabalho harmonioso e agradável.

\section{CONSIDERAÇÕES FINAIS}

A implantação do Programa 5S de Qualidade em um Serviço de Refeição ao Educandos apresentado nesse relato possibilitou não só uma organização físicalestrutural do ambiente, mas também uma melhor iluminação e ventilação, visto que a mesma foi reorganizada e seus excessos retirados. Foi também observado uma melhora nos processos já existentes, onde os 
mesmos foram padronizados e os colaboradores treinados para melhor executá-lo, aumentando assim a qualidade das refeições servidas e a qualidade de vida dos funcionários, pois o ambiente e as tarefas se tornaram menos estressantes e prática no decorrer dos dias. No setor gerencial, houve implantação de ferramentas para controlar estoque e custos da unidade, tendo como resultado um estoque equilibrado e uma lucratividade maior no final do mês.

A proposta aqui apresentada possui algumas limitações, especialmente relacionada ao curto espaço de tempo para a aplicação do programa, visto que o trabalho foi interrompido antes de alcançar os resultados esperado e alguns processos ainda precisariam ser revistos para atender as necessidades. Como proposta para continuidade do estudo sugere-se uma aplicação com uma durabilidade maior, visto que devido ao curto espaço de tempo não conseguiu observar outros possíveis resultados.

\section{REFERÊNCIAS}

BITENCOURT, C. O que é a metodologia 5s e como ela é utilizada - Sobre Administração. Disponível em: <http://www.sobreadministracao.com/o-que-e-a-metodologia-5s-e-como-elae-utilizada/>. Acesso em: 7 out. 2017a

CALEGARE, A. J. de A. Os mandamentos da Qualidade Total. 3. ed. Barueri: Inter-Qual International Quality Systems, 1999.

GOMES, D. et al. Aplicando 5S na gestão da qualidade total. São Paulo: Pioneira, 1998

Grupo Ferroeste > Notícias > Implantação do Programa 5S na GUSA Nordeste. Disponível em: $\quad<$ http://www.ferroeste.com.br/noticias/30/implantacao-do-programa-5s-na-gusanordeste>. Acesso em: 22 set. 2018.

HABU, N.; KOIZUMI Y.; OHMORI Y. Implementação do 5S na prática. Campinas: Editora Icea, 1992

IBGE | Brasil em Síntese. Disponível em: <https://cidades.ibge.gov.br/>. Acesso em: 6 out. 2017.

Itapira. Historia da cidade. 7 set. 2017. (Nota técnica).

JUNIOR, E B. M. I. M. et al. Gestão da qualidade e processos. Editora FGV, 2015.

LAPA, R. Programa 5S. Rio de Janeiro: Qualitymark, 1998

MASIERO, G. Empresa japonesa: estrutura, principais aspectos e processo decisório. 1994. Tese de Doutorado.

MITKI, Y.; SHANI, A. B. "Reengineering, total quality management and sociotechnical systems approaches to organization change: towards an eclectic approach?", Journal of Quality Management, v. 1, n. 2, p. 131-145, 1996.

Prefeitura Municipal de Itapira. Disponível em: <http://www.itapira.sp.gov.br/institucional/historia.jsp>. Acesso em: 6 out. 2017.

REBELLO, M. A. DE F. R. Implantação do Programa 5S para a conquista de um ambiente de qualidade na biblioteca do Hospital Universitário da Universidade de São Paulo. RDBCI: Revista Digital de Biblioteconomia e Ciência da Informação, v. 3, n. 2, p. 165-182, 2005.

RODRIGUES, M. V. C. Ações para a Qualidade.Rio de Janeiro. Editora Qualitymark, 2004. SILVA, M. Programa 5S - Qualidade Total. Fundação Educacional do Município de Assis Fema: Assis, 2011.

Univale implanta Programa 5S. Disponível em: <http://www.univalers.com.br/univaleimplanta-programa-5s/>. Acesso em: 22 set. 2018.

VANTI, N. A. P. Ambiente de qualidade em uma biblioteca universitária: aplicação do 5S e de um estilo participativo de administração. Ciência da Informação. Brasília. v.28, n.3, p. 331337, 1999. 